\title{
Erratum to: A systematic, large-scale comparison of transcription factor binding site models
}

Daniela Hombach ${ }^{1,2}$, Jana Marie Schwarz ${ }^{1,2}$, Peter N. Robinson ${ }^{3}$, Markus Schuelke ${ }^{1,2}$ and Dominik Seelow ${ }^{1,2,4^{*}}$

\section{Erratum}

Unfortunately, the original version of this article [1] contained an error. Figures 2 and 3 were interchanged. Figures 2 and 3 have been corrected in the original article and are also included correctly below.

\section{Author details}

'Department of Neuropaediatrics, Charité-Universitätsmedizin Berlin, Berlin, Germany. ${ }^{2}$ NeuroCure Clinical Research Center, Charité - Universitätsmedizin Berlin, Berlin, Germany. Institute for Medical Genetics and Human Genetics, Charité-Universitätsmedizin Berlin, Berlin, Germany. ${ }^{4}$ Berliner Institut für Gesundheitsforschung/Berlin Institute of Health, Berlin, Germany.

Published online: 20 July 2016

\section{Reference}

1. Hombach, et al. A systematic, large-scale comparison of transcription factor binding site models. BMC Genomics 2016;17:388. doi:10.1186/s12864-0162729-8

* Correspondence: dominik.seelow@charite.de

'Department of Neuropaediatrics, Charité-Universitätsmedizin Berlin, Berlin, Germany

${ }^{2}$ NeuroCure Clinical Research Center, Charité - Universitätsmedizin Berlin, Berlin, Germany (c) 2016 The Author(s). Open Access This article is distributed under the terms of the Creative Commons Attribution 4.0 International License (http://creativecommons.org/licenses/by/4.0/), which permits unrestricted use, distribution, and reproduction in any medium, provided you give appropriate credit to the original author(s) and the source, provide a link to the Creative Commons license, and indicate if changes were made. The Creative Commons Public Domain Dedication waiver (http://creativecommons.org/publicdomain/zero/1.0/) applies to the data made available in this article, unless otherwise stated.
Submit your next manuscript to BioMed Central and we will help you at every step:

- We accept pre-submission inquiries

- Our selector tool helps you to find the most relevant journal

- We provide round the clock customer support

- Convenient online submission

- Thorough peer review

- Inclusion in PubMed and all major indexing services

- Maximum visibility for your research

Submit your manuscript at

wuw.biomedcentral.com/submit 

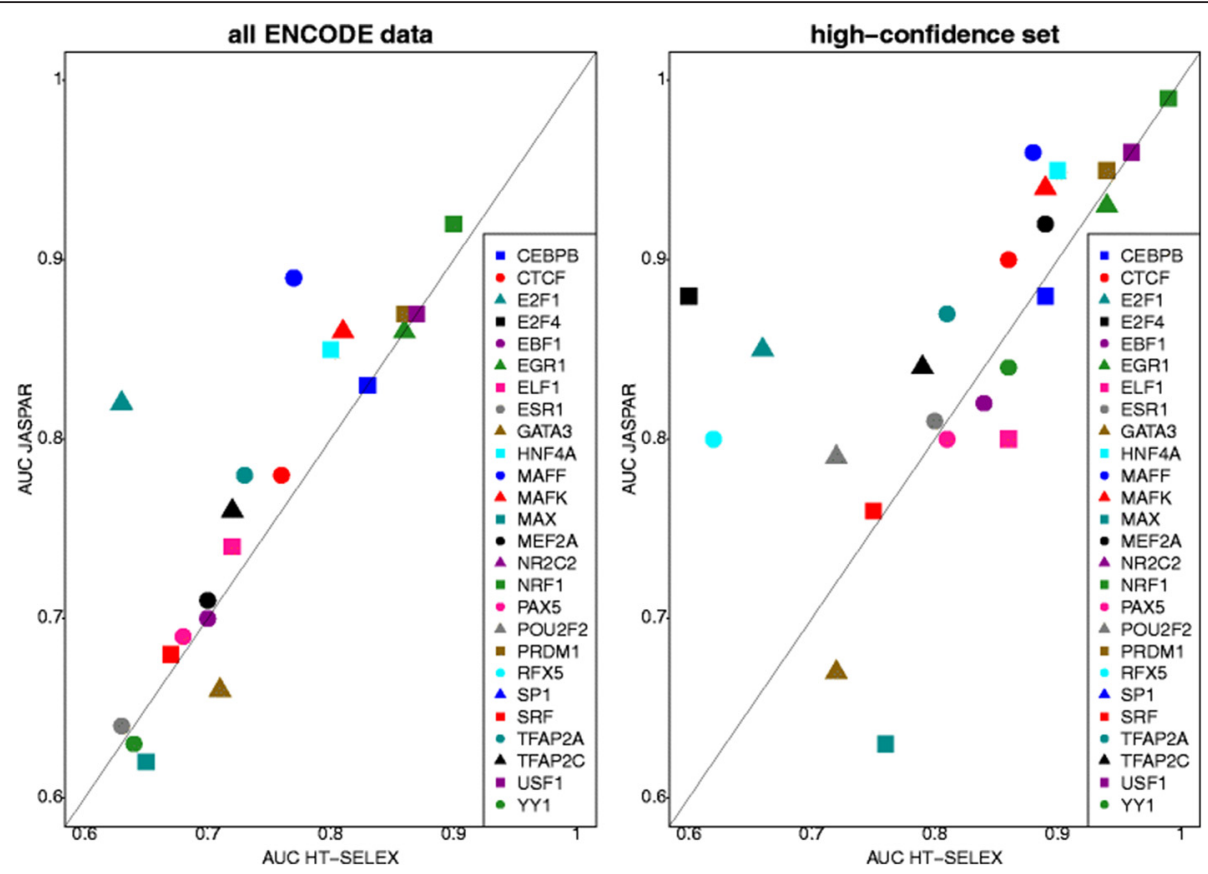

Fig. 2 Direct comparison of binding models generated by different methods. Depicted are AUC scores for TFs stored in both JASPAR (manually collected curated models) and HT-SELEX. AUC scores were generated using ROCR. If multiple binding models were available for one TF, we depict the average AUC value
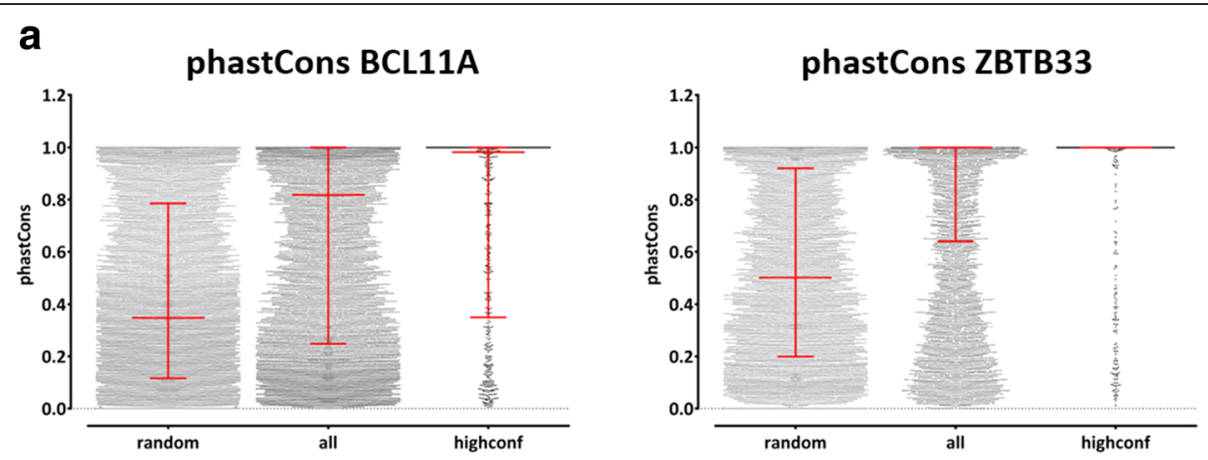

b

phyloP ZBTB33
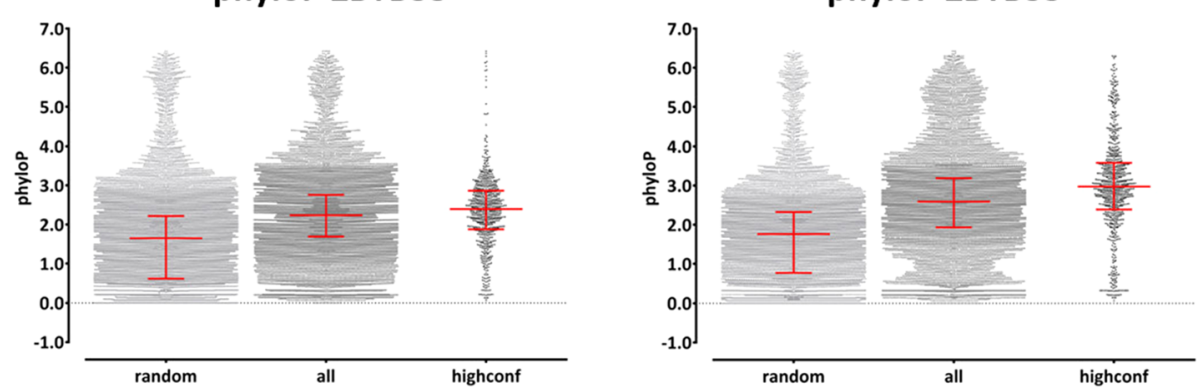

Fig. 3 Representative plots for conservation analyses. We determined the maximum phastCons (a) and phyloP (b) scores in each experimentally confirmed binding site of BCL11A (left panel) and ZBTB33 (right panel) and calculated the averages of the maximum scores 